\title{
Plumbagin Induces Cytotoxicity via Loss of Mitochondrial Membrane Potential and Caspase Activation in Metastatic Retinoblastoma
}

\author{
RAJENDRA GHARBARAN ${ }^{1}$, CUI SHI ${ }^{2,3}$, ONYEKWERE ONWUMERE ${ }^{2,3}$ and STEPHEN REDENTI ${ }^{2,3}$ \\ ${ }^{1}$ Department of Biological Sciences, Bronx Community College/City University of New York, New York, NY, U.S.A.; \\ ${ }^{2}$ Department of Biological Sciences, Lehman College/City University of New York, New York, NY, U.S.A.; \\ ${ }^{3}$ Biology Doctoral Program, The Graduate School and University Center, \\ City University of New York, New York, NY, U.S.A.
}

\begin{abstract}
Background/Aim: We investigated the cytotoxic effects of plumbagin on metastatic retinoblastoma, using the highly metastatic cell line Y79. Materials and Methods: Effect of plumbagin on cell growth was assessed with water-soluble tetrazolium 1 (WST-1) cell proliferation assay and automated hemocytometry with trypan blue-exclusion assay. Cell death was studied with acridine orangelethidium bromide live-dead assay and annexin-V-fluorescein isothiocyanatelpropidium iodide microscopy. Loss of mitochondrial membrane potential was studied with JC-10 dye and caspase activation was investigated using CellEvent Caspase-3/7 Green detection reagent. Results: Plumbagin highly significantly reduced the growth of Y79 cells treated for $24 \mathrm{~h}$ with $2.5 \mu \mathrm{M}$ or more. Plumbagin also induced significantly high levels of cell death which was associated with loss of mitochondrial membrane potential and caspase activation. Conclusion: At very low concentration $(2.5 \mu \mathrm{M})$, plumbagin potently induced cytotoxicity in metastatic retinoblastoma cells via loss of mitochondrial membrane potential and caspase activation.
\end{abstract}

Although retinoblastoma (RB) is considered a rare neoplasm, it remains the most common primary pediatric intraocular malignancy (1). The etiology of RB is not completed understood. However, the disease originates from the primitive retinal layer (2). Currently, RB has an excellent prognosis, with a $95 \%$ 5-year survival rate, however, predominantly only in

This article is freely accessible online.

Correspondence to: Rajendra Gharbaran, Associate Professor, Biological Sciences Department, Bronx Community College/The City University of New York, 2155 University Ave, Bronx, NY 10453, U.S.A. E-mail: rajendra.gharbaran@bcc.cuny.edu

Key Words: Metastatic retinoblastoma, Y79, plumbagin, cancer. developed countries (3) mainly due to improvement in treatment options which include chemotherapy, ophthalmectomy, laser therapy and cryotherapy (4). Despite this, the long-term survivors of RB face a life-long risk of development of secondary cancer, disease relapse and severe cytotoxic effects of chemotherapeutic drugs.

The long-term survival rates of patients with metastatic RB remain unsatisfactory, mainly a result of invasion and metastasis (5). The frequency of metastatic RB ranges from 4.8 to $11 \%$ (6, $7)$ and it remains major contributor to mortality and is associated with life-long poor prognosis $(6,8-11)$. Frequent common sites of extraocular RB include the orbit, pre-auricular nodes, bones, central nervous system and liver, and each of these may influence the outcome of metastatic RB. For example, RB diagnosis with orbital invasion is associated with a 10- to 27fold higher risk of metastasis when compared to cases without orbital extension (10-12). The clinical presentations are quite variable and depend on the site or sites involved.

Identifying and testing novel compounds with not only fewer side-effects but also with high therapeutic efficacy is important for improving the prognosis and outcome of patients with metastatic RB and long-term survivors of this malignancy. One such potential agent is plumbagin. Plumbagin (5-hydroxy-2methyl-1, 4-naphthoquinone, plumbagin) is an active compound found in the root of Plumbago zeylanica L, an Indian medicinal plant (13). A range of pharmacological activities including antimicrobial, hypolipidemic, and antitumor effects, have been ascribed to this compound (14-16). The antitumor activities have been demonstrated in a wide range of cancer types and cell lines, in in vitro and in vivo studies (17-21). However, despite the growing body of studies on the antitumor effect of plumbagin, there are no reports on the cytotoxic responses of metastatic retinoblastoma to this compound.

In this study, we investigated the potential cytotoxic effects of plumbagin in metastatic RB, using the highly metastatic RB cell line Y79. 

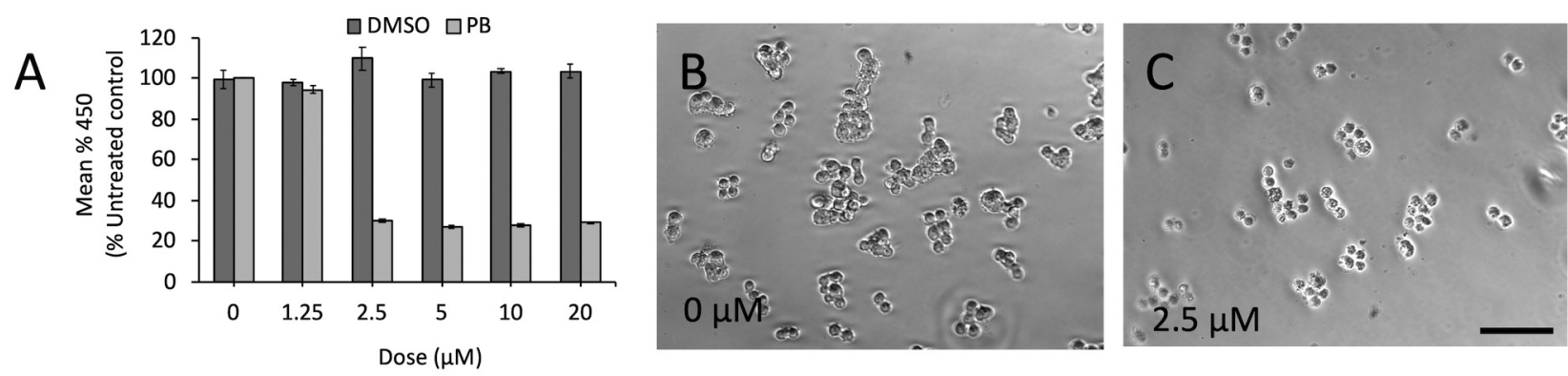

Figure 1. Effect of plumbagin (PB) on the growth of Y79 cells. A: WST-1 cell proliferation assay showed highly significant decrease in growth of $P B$-treated cells compared to DMSO controls $(p<0.0001)$. At doses of $2.5 \mu M P B$ and above, the growth of Y79 cells remained statistically unchanged $(p>0.05)$. Results are presented as the mean \pm standard error. B: Phase-contrast image showing characteristic cellular morphology of untreated Y79 cells. C: Phase-contrast image depicting compromised membranes of Y79 cells treated with $2.5 \mu M$ PB for 24 h. Scale bar=50 $\mu \mathrm{m}$.

\section{Methods and Materials}

Drug. Plumbagin was purchased from Cayman Chemicals (Ann Arbor, MI, USA) and dissolved in dimethyl sulfoxide (DMSO; SigmaAldrich, St. Louis, MO, USA) to prepare a 50-mM stock, which was aliquoted and stored at $-20^{\circ} \mathrm{C}$ until used. All working stocks of plumbagin were prepared to a final concentration of $0.01 \%$ DMSO.

Cell lines and cell cultures. The human-derived metastatic RB cell line Y79 was obtained from the American Tissue and Cell Collection (Manassas, VA, USA). The cells were cultured in RPMI 1640 medium supplemented with $20 \%$ heat-inactivated fetal bovine serum (Gibco, Gaithersburg, MD, USA), 1\% L-glutamine (Thermo Fisher Scientific, Waltham, MA, USA) and penicillin/streptomycin (Thermo Fisher Scientific). All cells were maintained in a humid environment with $5 \% \mathrm{CO}_{2}$ at $37^{\circ} \mathrm{C}$.

WST-1 cell proliferation assay. Cell growth was assessed with WST1 cell proliferation assay (Roche, Branchburg, NJ, USA), according to the manufacturer's instructions and as described by Gharbaran et al. (22). One hundred microliters of medium containing cells at $1 \times 10^{5}$ cells $/ \mathrm{ml}$ were seeded in a 96-well plate, and incubated overnight. Cells were then treated with $0,1.25,2.5,5,10$ and $20 \mu \mathrm{M}$ of plumbagin or DMSO for $24 \mathrm{~h}$. The treated cells were incubated with $10 \mu \mathrm{l}$ WST-1 reagent for $3 \mathrm{~h}$ following standard cell culture conditions. Absorbance was read at $450 \mathrm{~nm}$ on a Synergy H1 Hybrid microplate reader (BioTek Instruments, Winooski, VT, USA). Cell growth (as a percentage) was computed as a ratio of the absorbance (A450) of treated (either plumbagin or DMSO) cells to the absorbance of the untreated $(0 \mu \mathrm{M})$ control. The assay principle is based on the conversion of the tetrazolium salt WST-1 into a colored dye by mitochondrial dehydrogenase enzymes.

Acridine orange (AO) and ethidium bromide (EtBr) liveldead assay. $\mathrm{AO} / \mathrm{EtBr}$ assay was used to determine cell death. Five hundred microliters of medium containing cells at $2 \times 10^{5}$ cells $/ \mathrm{ml}$ were seeded in poly-L-lysine (Sigma-Aldrich)-coated 20-mm microwells of $35 \mathrm{~mm}$ petri dish (MatTek Corporation, Ashland, MA, USA) overnight and then treated with 0 and $2.5 \mu \mathrm{M}$ plumbagin, for $24 \mathrm{~h}$. Twenty microliters of a solution consisting of $100 \mu \mathrm{g} / \mathrm{ml}$ each of $\mathrm{AO}$ and $\mathrm{EtBr}$ were then added to each well and dishes were immediately imaged. In this assay, the membrane-permeable AOstained live cells green and $\mathrm{EtBr}$, which is membrane-impermeable, stained the nuclei of dead cells orange to red.

Annexin V fluorescein isothiocyanate (FITC)-propidium iodide (PI) assay. Annexin V-PI staining was carried out using Annexin V FITC Assay Kit (Cayman Chemicals), according to the manufacturer's instructions. One hundred microliters of medium containing cells at $1 \times 10^{5}$ cells $/ \mathrm{ml}$ were seeded in 96 -well plates overnight and treated with 0 and $2.5 \mu \mathrm{M}$ plumbagin for $24 \mathrm{~h}$. Treated cells were transferred to a microfuge tube and collected by centrifugation at $400 \times g$ for 5 min at room temperature, and then resuspended in $100 \mu \mathrm{l} 1 \mathrm{X}$ binding buffer. Cells were then centrifuged as described and incubated in $50 \mu \mathrm{l}$ annexin V FITC/PI staining solution for $10 \mathrm{~min}$ at room temperature in a dark chamber. Stained cells were collected by centrifugation and resuspended in binding buffer. Cells were then transferred to chamber slides containing poly D-lysine for analysis by microscopy.

Detection of mitochondrial membrane potential $\left(\Psi_{m}\right)$. Changes in $\Psi \mathrm{m}$ were assessed by staining treated cells with JC-10 dye according to the manufacturer's (Sigma-Aldrich) instruction. Five hundred microliters of medium containing cells at $1 \times 10^{5}$ cells $/ \mathrm{ml}$ was seeded and treated as described for $\mathrm{AO} / \mathrm{EtBr}$ assay. The cells were then incubated in JC-10 Dye Loading Solution for $30 \mathrm{~min}$ following standard cell culture condition. An aliquot $(250 \mu \mathrm{l})$ of the JC-10 Dye Loading Solution-medium mix was withdrawn and replaced with 250 $\mu \mathrm{l}$ Assay Buffer B. Cells were immediately imaged.

Detection of caspase activities. Caspase 3/7 activities were analyzed using CellEvent Caspase-3/7 Green Detection Reagent (Life Technologies, CA, USA), according to manufacturer's instructions. Cells were seeded and treated as described for AO/EtBr live-dead assay. Cells were then incubated with CellEvent Caspase-3/7 Green Detection Reagent at a final concentration of $4 \mu \mathrm{M}$ for $30 \mathrm{~min}$, following standard cell culture conditions.

Microscopy. Microscopy was carried out as previously described (22). Images for live/dead assay, caspase 3/7 activation, and annexin V-FITC/PI analyses were generated from randomly selected fields. Approximately 5 to 15 fields were imaged per dose. Cell counts on 
A

$\mathrm{PB}$

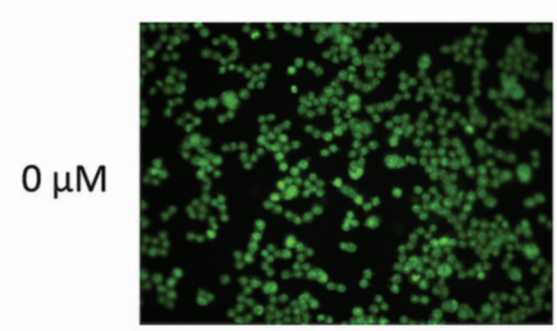

$2.5 \mu \mathrm{M}$

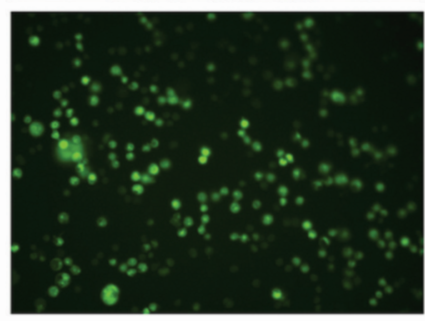

$\mathrm{EtBr}$
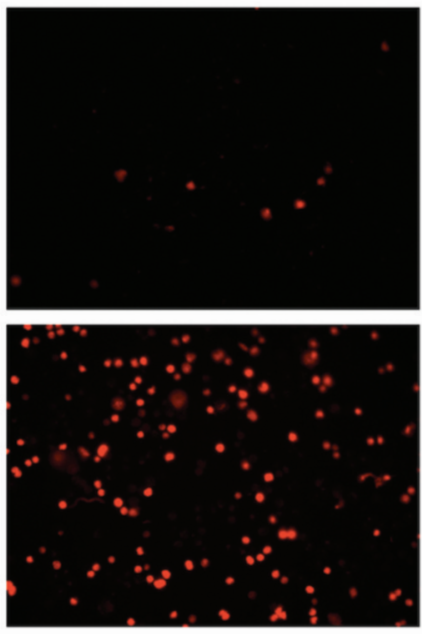

Merge
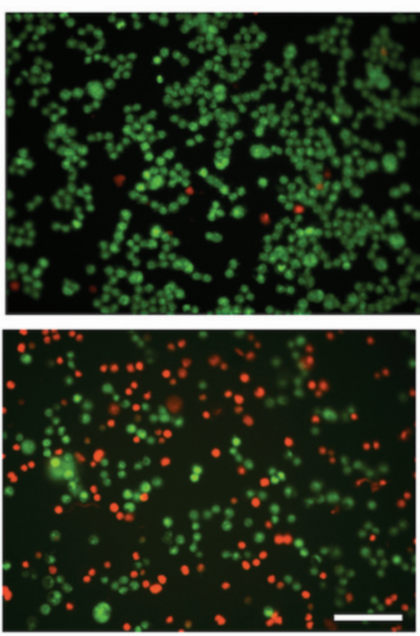

B

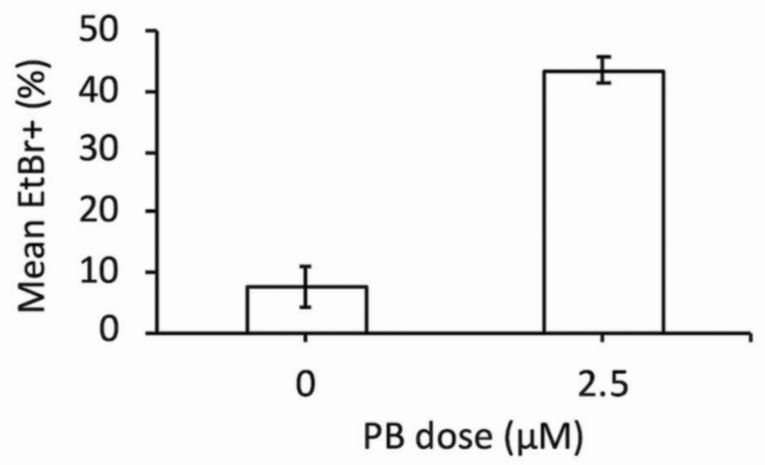

Figure 2. Detection of plumbagin (PB)-induced cell death with acridine orange/ethidium bromide (AO/Etbr) live-dead assay. A: AO/EtBr staining of Y79 cells treated with $P B$ at $O$ and $2.5 \mu M$ for 24 h. B: AO/EtBr staining revealed a significantly higher proportion of dead cells (EtBr+, red) due to $P B$ treatment compared to untreated cells $(0 \mu M)(p<0.0001)$. Results are presented as the mean \pm standard error. Scale bar $=50 \mu m$.

images were carried out manually, blindly, by independent counters. However, for $\mathrm{AO} / \mathrm{EtBr}$ and caspase detection assays, the cell count was carried out on the upper left quadrant of each field.

Statistical analyses. Data analyses were performed using StatView 5 (Cary, NC, USA). Analysis of variance was used to determine significant differences between the means as defined by $p<0.05$ Data obtained from the assays on cell growth, $\mathrm{AO} / \mathrm{EtBr}$, annexin $\mathrm{V}$ PI, caspase $3 / 7$, are presented as the mean and standard error of the mean. For the cell growth assay, the mean value was determined from triplicates per dose. Each experiment was repeated at least three times.

\section{Results}

Effect of plumbagin on cell growth of metastatic retinoblastoma. As a first step, we tested different concentrations of plumbagin on the growth of Y79 cells treated for $24 \mathrm{~h}$. WST-1 cell proliferation assay showed plumbagin potently and significantly inhibited cell growth at doses of $2.5 \mu \mathrm{M}$ and above compared to cells treated with DMSO (vehicle) equivalent (Figure 1A). However, the plumbagin-induced inhibition of cell growth was not dose-dependent; there was no statistical difference in cell growth for doses of $2.5,5,10$, and $20 \mu \mathrm{M}$. We also assessed cell growth independently with automated hemocytometry via trypan blue exclusion assay. The results were similar to those of the WST-1 cell proliferation assay (data not shown). Phasecontrast microscopy showed plumbagin-treated cells with compromised membranes which was absent from untreated and DMSO controls (Figure 1B and C, respectively), suggesting loss of cell viability associated this compound. In these experiments, the lack of effect on cell growth by the DMSO equivalent indicates that the solvent did not affect cell viability nor did it cause cytotoxicity to the Y79 cells. As a result, we 
A

$\mathrm{PB}$ Annexin V-FITC

PI

\section{Merge}
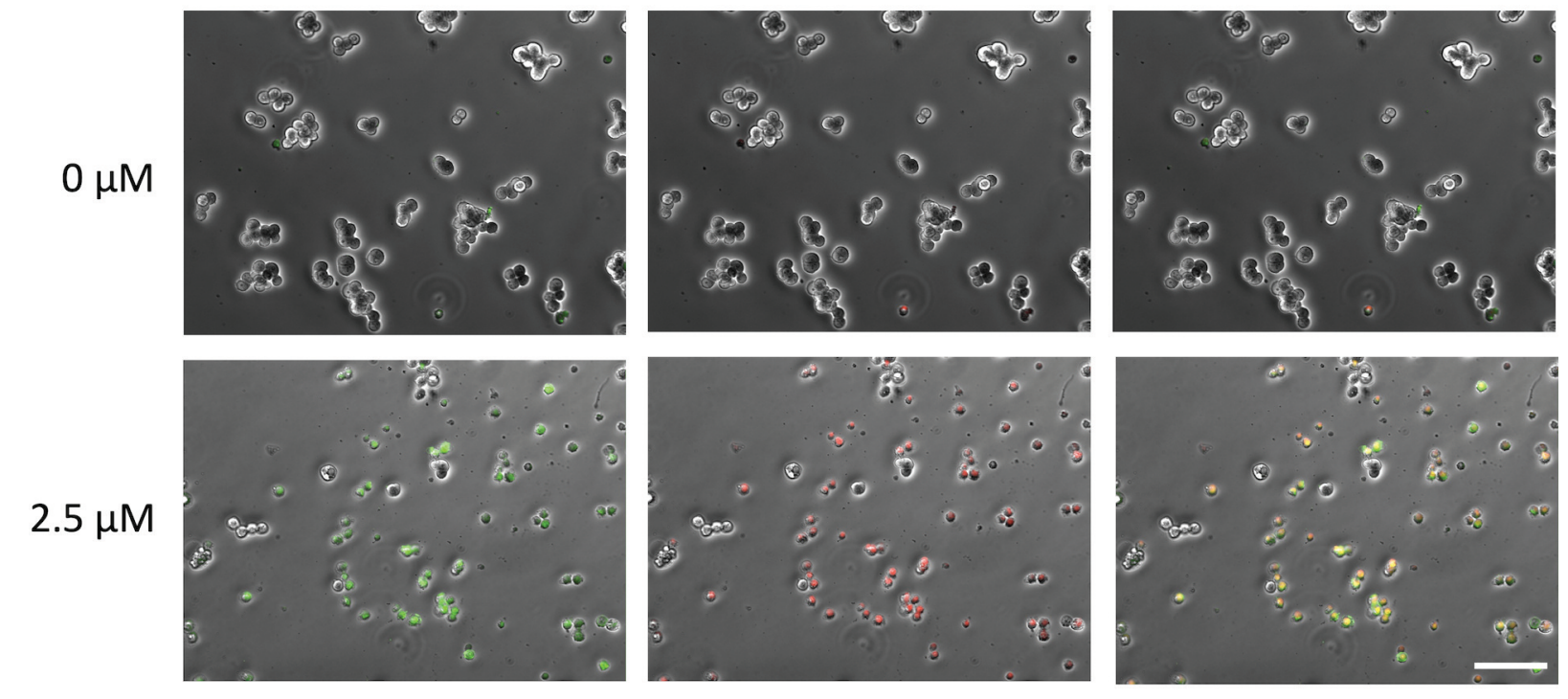

B

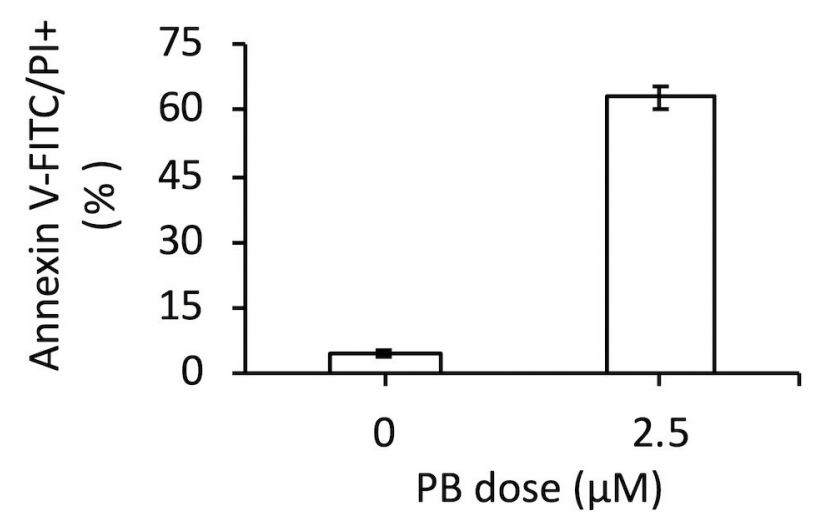

Figure 3. Detection of apoptotic cells with annexin V-fluorescein isothiocyanate (FITC)/propidium iodide (PI) staining. A: Detection of apoptotic $Y 79$ cells after treatment with plumbagin $(P B)$ at 0 and $2.5 \mu M$ for 24 h by annexin V-FITC/PI staining. B: A significantly higher proportion of annexin V-FITC/PI+ cells (stained green and red, respectively) was detected for Y79 cells treated with $2.5 \mu M$ PB compared to untreated cells. Results are presented as the mean \pm standard error. Scale bar in $A=50 \mu \mathrm{m}$.

focused our attention on cytotoxicity induced by plumbagin at the lower dose $(2.5 \mu \mathrm{M})$ in subsequent experiments.

Plumbagin induced cell death. We next determined whether plumbagin-induced reduced cell growth was partly a consequence of cell death. AO-EtBr staining showed significant cell death (red-orange) in cells treated with $2.5 \mu \mathrm{M}$ of plumbagin for $24 \mathrm{~h}$ (Figure 2A). As shown in Figure 2B, the mean proportion of $\mathrm{EtBr}+$ cells on 24-h treatment with $2.5 \mu \mathrm{M}$ plumbagin was $43.50 \%( \pm 2.19 \%)$ compared to the untreated control $(7.69 \% \pm 3.31 \%)(p<0.0001)$. plumbagin-induced cell death was further investigated with Annexin V-FITC/PI microscopy. As shown in Figure 3, Annexin V-PI positive cells were significantly higher in plumbagin-treated Y79 cells $(62.97 \% \pm 2.80)$ compared to $0 \mu \mathrm{M}(4.86 \% \pm 0.93 \%)(p<0.0001)$.

Plumbagin reduced $\Psi_{m}$. Loss of $\Psi \mathrm{m}$ is an early biochemical indicator of apoptotic cell death. To determine the effects of plumbagin on the function of mitochondria, $\Delta \Psi \mathrm{m}$ was assessed after $24 \mathrm{~h}$ treatment of Y79 cells. JC-10, a cationic dye which accumulates potential-dependently in mitochondria, was used to study changes in $\Psi \mathrm{m}$. Under the microscope, JC- 
PB

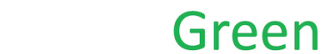

Red
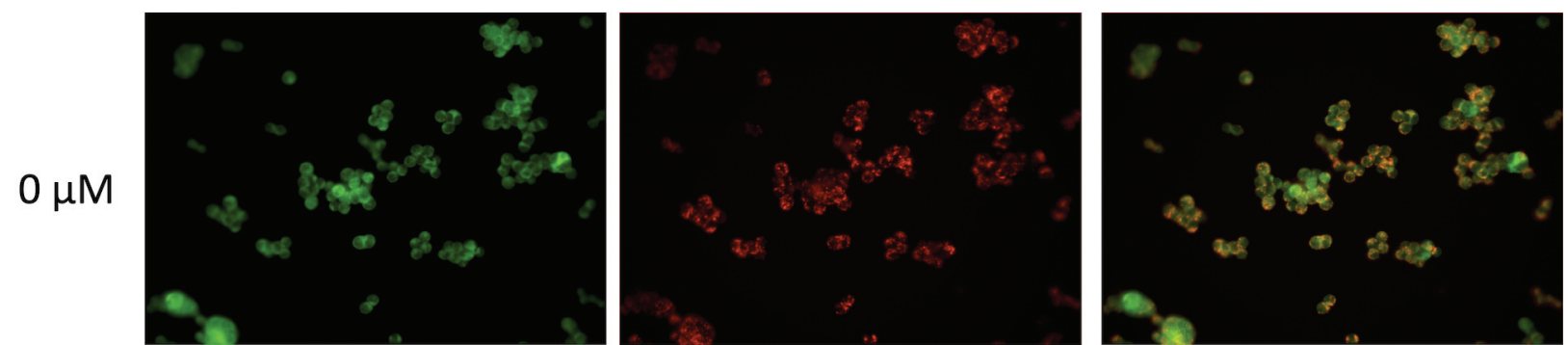

$2.5 \mu \mathrm{M}$
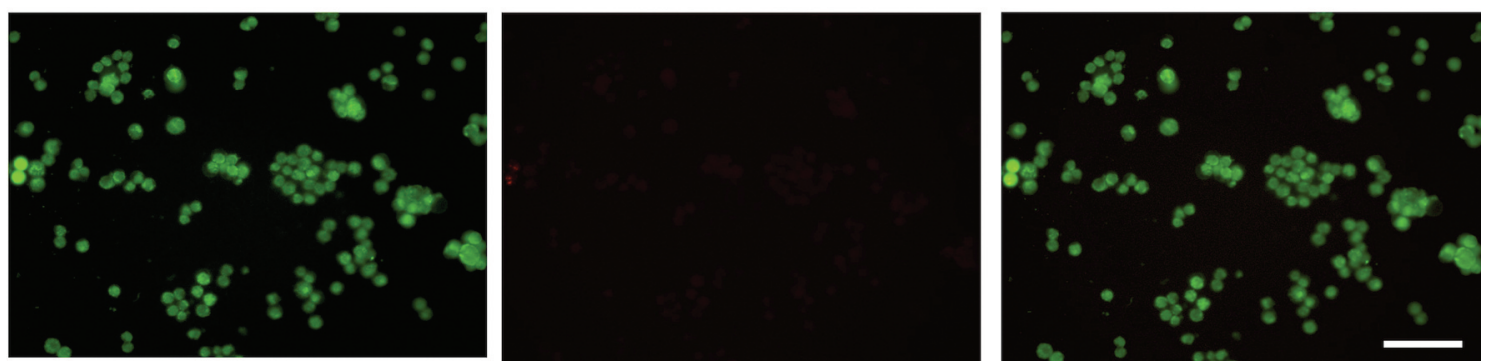

Figure 4. Plumbagin $(P B)$ induces loss of mitochondrial membrane potential. Staining of Y79 cells treated with $2.5 \mu M$ PB for $24 \mathrm{~h}$ with JC-10 dye showed loss of mitochondrial membrane potential (absence of red fluorescence and presence of green fluorescence - lower panel) compared to untreated $(0 \mu \mathrm{M})$ cells (presence of both red and green fluorescent signals in upper panel). Scale bar=50 $\mu m$.

10 fluoresces green $(540 \mathrm{~nm})$ when the $\Psi \mathrm{m}$ is lower than 140 $\mathrm{mV}$ and at higher membrane potential, the dye fluoresces red. With this dye, the loss of $\Psi \mathrm{m}$ is followed by a red-to-green shift. Therefore, microscopically, live cells stained with JC-10 dye contain red puncta or aggregates which are absent from or diminished in dead cells, which stain predominantly green with the dye. In our experiments, control cells $(0 \mu \mathrm{M}$ plumbagin) exhibited red aggregates which were absent from cells treated plumbagin at $2.5 \mu \mathrm{M}$ for $24 \mathrm{~h}$ (Figure 4).

Caspase activation. Activation of the caspase cascade is another important molecular hallmark of apoptosis. To determine whether plumbagin-induced cell death progresses via caspase activation, we stained Y79 cells incubated with plumbagin for $24 \mathrm{~h}$ with a caspase $3 / 7$-specific fluorochrome detection dye. The staining revealed a significantly higher proportion of caspase 3/7-positive (stained green) plumbagin-treated Y79 cells $(50.71 \% \pm 4.93 \%)$ compared to untreated controls $(5.11 \% \pm 0.63 \%)(p<0.0001)$ (Figure 5).

\section{Discussion}

Although RB has an excellent prognosis, with a 95\% 5-year survival rate, this is predominantly only for patients in developed countries (3), the prognosis in developing countries remaining relatively poor. In addition, long-term survivors of RB with metastatic phenotype bear the risk of emergence of secondary neoplasms, and life-threatening toxicities directly related to chemotherapy. To address these concerns, one line of RB research involves the identification of novel agents with less toxicity but high efficacy.

In the current study, we demonstrated that plumbagin potently induced cytotoxicity in metastatic RB and this process was associated with loss of mitochondrial membrane potential and caspase activation. Our WST-1 cell proliferation assay showed that plumbagin significantly restricted the growth of Y79 cells at $2.5 \mu \mathrm{M}$, after $24 \mathrm{~h}$, an indication of the strong antitumor potency of this compound. Cell growth at higher doses of plumbagin was not statistically different from that at $2.5 \mu \mathrm{M}$. The plumbagin-induced growth inhibition noted in our study differs from that of some other reports. In vitro study showed that plumbagin inhibited growth of esophageal cancer cells in a dose-dependent manner (at comparable doses as our study) (23). Studies in other cancer types also report dose-dependent inhibition of cancer cell growth by plumbagin $(24,25)$.

Induction of apoptosis is an important hallmark in cancer therapy. In multiple cancer types, plumbagin limits cell growth by inducing apoptosis (26-30). In our study, treatment of Y79 metastatic RB cells with plumbagin for $24 \mathrm{~h}$ resulted in statistically significant levels of cell death, as evident by our AO-EtBr live-dead staining and annexin $\mathrm{V}$ assays. This level of cell death was evident at $2.5 \mu \mathrm{M}$ plumbagin and above. 
A

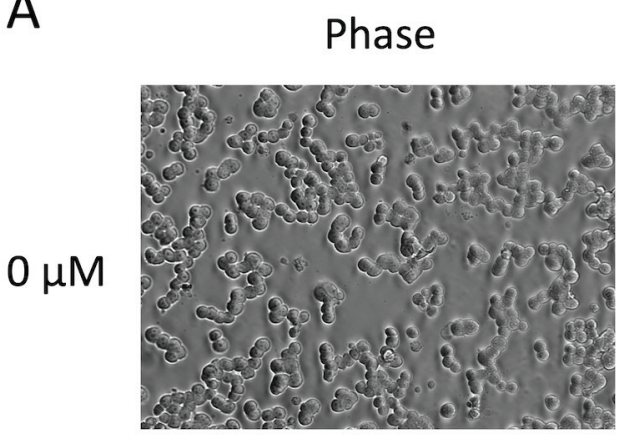

Phase

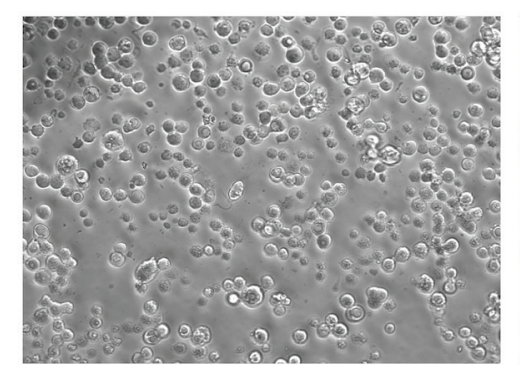

\section{Casp3/7}
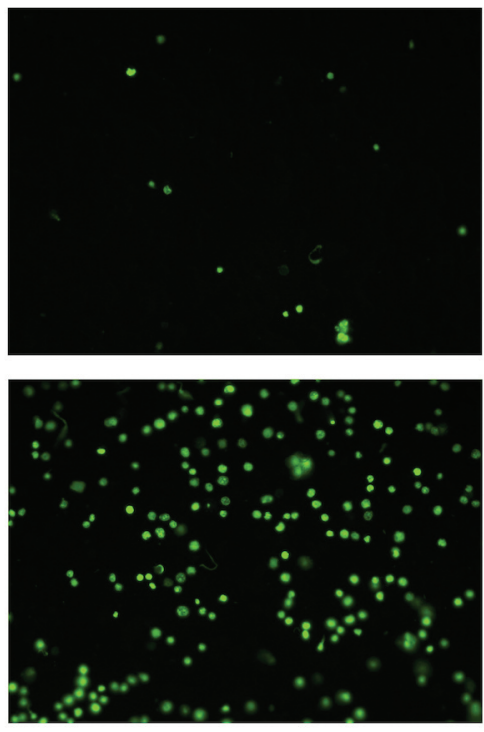

Merge
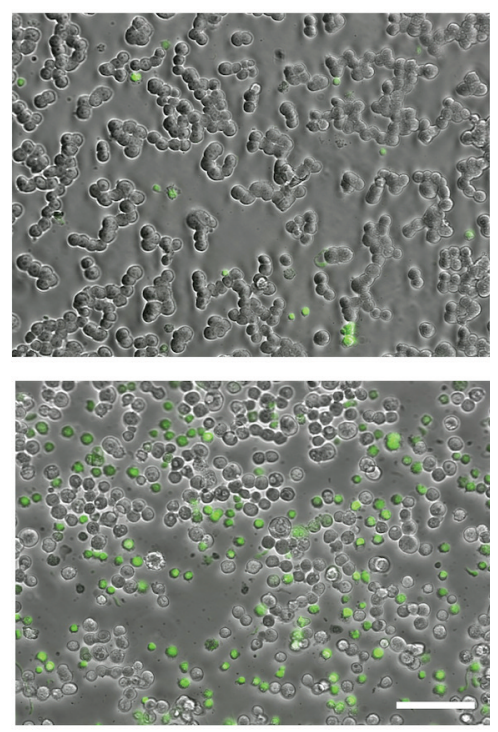

B

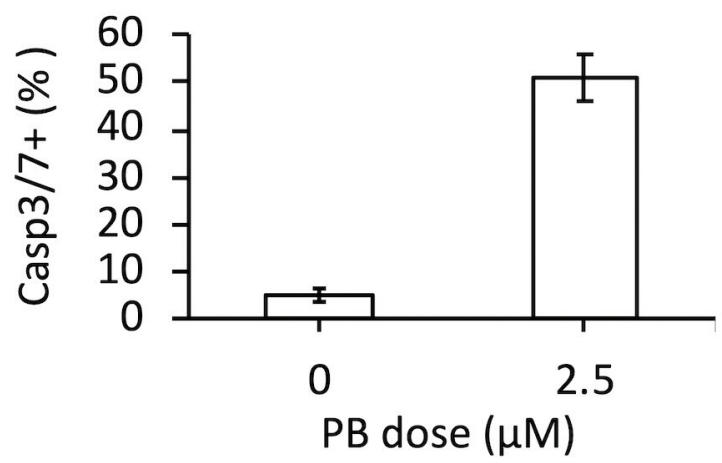

Figure 5. Effect of plumbagin (PB) on caspase 3/7 (Casp3/7+) activity in Y79 cells. A: Detection of Casp3/7+-positive (green) cells after treatment for $24 \mathrm{~h}$ with 0 and $2.5 \mu M$ PB. B: A highly significant proportion of Casp3/7+ cells were detected in PB-treated cells compared to untreated cells $(p<0.0001)$. Results are presented as the mean \pm standard error. Scale bar $=50 \mu \mathrm{m}$.

In general, programmed cell death is driven by two types of apoptotic pathways, namely the death receptor-dependent extrinsic pathway and a mitochondrial-dependent intrinsic pathway (31). Mitochondrial-mediated apoptosis involves disruption of mitochondrial membrane, resulting in loss of $\Psi \mathrm{m}$, and cytochrome c release from mitochondria into the cytosol (32). One consequence of this is the the activation of the caspase 9/caspase 3 pathway, leading to chromatin condensation and DNA fragmentation (33). In our study, loss of $\Psi \mathrm{m}$ was observed after plumbagin treatment, as evident by either the reduction or absence of red fluorescence in treated cells compared with untreated cells, following staining with JC-10 dye. In addition, in our study, plumbagin-treated cells had statistically significantly higher levels of caspase- positive cells (Figure 5) following staining with a caspase 3/7-specific dye. These results suggested that plumbagininduced apoptosis in metastatic RB likely involves the loss of $\Psi \mathrm{m}$ and caspase 3/7 activation, which are associated with the mitochondrial-mediated intrinsic cell death pathway.

There are some limitations of the current study. The lack of cell-cycle analyses precludes determination of whether plumbagin induces cell-cycle arrest, and by extension, studies into the mechanism(s) of action. In addition, assaying for cytochrome c release, which is associated with loss of $\Psi \mathrm{m}$, was not carried out. Moreover, other hallmarks of apoptosis such as chromatin condensation and DNA fragmentation were not studied. Despite these limitations, the results from our cytotoxic assays highlight the significance 
of plumbagin as a potential agent that can be developed for treating metastatic RB. However, future studies are required to determine the molecular details of plumbagin-induced cell death and potential cell-cycle arrest in this malignancy.

\section{Conflicts of Interest}

The Authors declare no conflicts of interest regarding this study.

\section{Authors' Contributions}

RG conceptualized the project, designed and conducted experiments, interpreted data and wrote the article. OO and CS conducted experiments. RG, OO and SR interpreted data. All Authors read and approved the final article.

\section{Acknowledgements}

Support for this project was provided in part by a PSC-CUNY Award, jointly funded by The Professional Staff Congress and The City University of New York (Award \#: TRADB-48-360), and The City University of New York Community College Research Grant (Award \#: 80212-03-17).

\section{References}

1 Dimaras H, Corson TW, Cobrinik D, White A, Zhao J, Munier FL, Abramson DH, Shields CL, Chantada GL, Njuguna F and Gallie BL: Retinoblastoma. Nat Rev Dis Primers 1: 15021, 2015. PMID: 27189421. DOI: 10.1038/nrdp.2015.21

2 Dimaras H, Kimani K, Dimba EA, Gronsdahl P, White A, Chan HS and Gallie BL: Retinoblastoma. Lancet 379(9824): 14361446, 2012. PMID: 22414599. DOI: 10.1016/S01406736(11)61137-9

3 Abramson DH, Fabius AW, Issa R, Francis JH, Marr BP, Dunkel IJ and Gobin YP: Advanced unilateral retinoblastoma: The impact of ophthalmic artery chemosurgery on enucleation rate and patient survival at MSKCC. PLoS One 10(12): e0145436, 2015. PMID: 26709699. DOI: 10.1371/journal.pone.0145436

4 Ramírez-Ortiz MA, Lansingh VC, Eckert KA, Haik BG, Phillips BX, Bosch-Canto V, González-Pérez G, Villavicencio-Torres A and Etulain-González A: Systematic review of the current status of programs and general knowledge of diagnosis and management of retinoblastoma. Bol Med Hosp Infant Mex 74(1): 41-54, 2017. PMID: 29364813. DOI: 10.1016/j.bmhimx.2016.08.002

5 Abramson DH, Shields CL, Munier FL and Chantada GL: Treatment of retinoblastoma in 2015: Agreement and disagreement. JAMA Ophthalmol 133(11): 1341-1347, 2015. PMID: 26378747. DOI: 10.1001/jamaophthalmol.2015.3108

6 Cozza R, De Ioris MA, Ilari I, Devito R, Fidani P, De Sio L, Demelas F, Romanzo A and Donfrancesco A: Metastatic retinoblastoma: single institution experience over two decades. Br J Ophthalmol 93(9): 1163-1166, 2009. PMID: 19556217. DOI: $10.1136 /$ bjo.2008.148932

7 Gündüz AK, Mirzayev I, Temel E, Ünal E, Taçyıldız N, Dinçaslan H, Köse SK, Özalp Ateş FS and Işık MU: A 20-year audit of retinoblastoma treatment outcomes. Eye (Lond) 34(10): 19161924, 2020. PMID: 32376976. DOI: 10.1038/s41433-020-0898-9
8 Gündüz K, Müftüoglu O, Günalp I, Unal E and Taçyildiz N: Metastatic retinoblastoma clinical features, treatment, and prognosis. Ophthalmology 113(9): 1558-1566, 2006. PMID: 16828510. DOI: $10.1016 /$ j.ophtha.2006.03.039

9 Finger PT, Harbour JW and Karcioglu ZA: Risk factors for metastasis in retinoblastoma. Surv Ophthalmol 47(1): 1-16, 2002. PMID: 11801265. DOI: 10.1016/s0039-6257(01)00279-x

10 Choucair ML, Brisse HJ, Fréneaux P, Desjardins L, Dorfmüller G, Puget S, Dendale R, Chevrier M, Doz F, Lumbroso-Le Rouic $\mathrm{L}$ and Aerts I: Management of advanced uni- or bilateral retinoblastoma with macroscopic optic nerve invasion. Pediatr Blood Cancer 67(1): e27998, 2020. PMID: 31571399. DOI: $10.1002 /$ pbc. 27998

11 Honavar SG and Singh AD: Management of advanced retinoblastoma. Ophthalmol Clin North Am 18(1): 65-73, viii, 2005. PMID: 15763192. DOI: 10.1016/j.ohc.2004.09.001

12 Atchaneeyasakul LO, Wongsiwaroj C, Uiprasertkul M, Sanpakit $\mathrm{K}$, Thephamongkhol $\mathrm{K}$ and Trinavarat A: Prognostic factors and treatment outcomes of retinoblastoma in pediatric patients: a single-institution study. Jpn J Ophthalmol 53(1): 35-39, 2009. PMID: 19184307. DOI: 10.1007/s10384-008-0614-y

13 Tilak JC, Adhikari S and Devasagayam TP: Antioxidant properties of Plumbago zeylanica, an Indian medicinal plant and its active ingredient, plumbagin. Redox Rep 9(4): 219-227, 2004. PMID: 15479566. DOI: 10.1179/135100004225005976

14 Nair SV, Baranwal G, Chatterjee M, Sachu A, Vasudevan AK, Bose C, Banerji A and Biswas R: Antimicrobial activity of plumbagin, a naturally occurring naphthoquinone from Plumbago rosea, against Staphylococcus aureus and Candida albicans. Int J Med Microbiol 306(4): 237-248, 2016. PMID: 27212459. DOI: 10.1016/j.ijmm.2016.05.004

15 Pai SA, Munshi RP, Panchal FH, Gaur IS, Mestry SN, Gursahani MS and Juvekar AR: Plumbagin reduces obesity and nonalcoholic fatty liver disease induced by fructose in rats through regulation of lipid metabolism, inflammation and oxidative stress. Biomed Pharmacother 111: 686-694, 2019. PMID: 30611993. DOI: 10.1016/j.biopha.2018.12.139

16 Zhang XQ, Yang CY, Rao XF and Xiong JP: Plumbagin shows anti-cancer activity in human breast cancer cells by the upregulation of p53 and p21 and suppression of G1 cell cycle regulators. Eur J Gynaecol Oncol 37(1): 30-35, 2016. PMID: 27048106.

17 Fu C, Gong Y, Shi X, Sun Z, Niu M, Sang W, Xu L, Zhu F, Wang $\mathrm{Y}$ and $\mathrm{Xu} \mathrm{K}$ : Plumbagin reduces chronic lymphocytic leukemia cell survival by downregulation of $\mathrm{Bcl}-2$ but upregulation of the Bax protein level. Oncol Rep 36(3): 16051611, 2016. PMID: 27461100. DOI: 10.3892/or.2016.4950

18 Abedinpour P, Baron VT, Chrastina A, Rondeau G, Pelayo J, Welsh $\mathrm{J}$ and Borgström P: Plumbagin improves the efficacy of androgen deprivation therapy in prostate cancer: A pre-clinical study. Prostate 77(16): 1550-1562, 2017. PMID: 28971491. DOI: $10.1002 /$ pros. 23428

19 Sakunrangsit N and Ketchart W: Plumbagin inhibited AKT signaling pathway in HER-2 overexpressed-endocrine resistant breast cancer cells. Eur J Pharmacol 868: 172878, 2020. PMID: 31863768. DOI: 10.1016/j.ejphar.2019.172878

20 Sinha S, Pal K, Elkhanany A, Dutta S, Cao Y, Mondal G, Iyer S, Somasundaram V, Couch FJ, Shridhar V, Bhattacharya R, Mukhopadhyay D and Srinivas P: Plumbagin inhibits tumorigenesis and angiogenesis of ovarian cancer cells in vivo. 
Int J Cancer 132(5): 1201-1212, 2013. PMID: 22806981 . DOI: $10.1002 / \mathrm{ijc} .27724$

21 Sakpakdeejaroen I, Somani S, Laskar P, Mullin M and Dufès C: Regression of melanoma following intravenous injection of plumbagin entrapped in transferrin-conjugated, lipid-polymer hybrid nanoparticles. Int J Nanomedicine 16: 2615-2631, 2021. PMID: 33854311. DOI: 10.2147/IJN.S293480

22 Gharbaran R, Zhang B, Valerio L, Onwumere O, Wong M, Mighty J and Redenti S: Effects of vitamin D3 and its chemical analogs on the growth of Hodgkin's lymphoma, in vitro. BMC Res Notes 12(1): 216, 2019. PMID: 30961641. DOI: 10.1186/s13104-019-4241-0

23 Cao YY, Yu J, Liu TT, Yang KX, Yang LY, Chen Q, Shi F, Hao JJ, Cai Y, Wang MR, Lu WH and Zhang Y: Plumbagin inhibits the proliferation and survival of esophageal cancer cells by blocking STAT3-PLK1-AKT signaling. Cell Death Dis 9(2): 17, 2018. PMID: 29339720. DOI: 10.1038/s41419-017-0068-6

24 Subramaniya BR, Srinivasan G, Sadullah SS, Davis N, Subhadara LB, Halagowder D and Sivasitambaram ND: Apoptosis inducing effect of plumbagin on colonic cancer cells depends on expression of COX-2. PLoS One 6(4): e18695, 2011. PMID: 21559086. DOI: 10.1371/journal.pone.0018695

25 Yan W, Wang TY, Fan QM, Du L, Xu JK, Zhai ZJ, Li HW and Tang TT: Author Correction: Plumbagin attenuates cancer cell growth and osteoclast formation in the bone microenvironment of mice. Acta Pharmacol Sin 41(4): 581-582, 2020. PMID: 31383989. DOI: 10.1038/s41401-019-0252-6

26 Yin Z, Zhang J, Chen L, Guo Q, Yang B, Zhang W and Kang $\mathrm{W}$ : Anticancer effects and mechanisms of action of plumbagin: review of research advances. Biomed Res Int 2020: 6940953, 2020. PMID: 33344645. DOI: 10.1155/2020/6940953

27 Zhang X, Kan H, Liu Y and Ding W: Plumbagin induces Ishikawa cell cycle arrest, autophagy, and apoptosis via the PI3K/Akt signaling pathway in endometrial cancer. Food Chem Toxicol 148: 111957, 2021. PMID: 33383144. DOI: 10.1016/ j.fct.2020.111957
28 Chen H, Wang H, An J, Shang Q and Ma J: Plumbagin induces RPE cell cycle arrest and apoptosis via p38 MARK and $\mathrm{PI} 3 \mathrm{~K} / \mathrm{AKT} / \mathrm{mTOR}$ signaling pathways in PVR. BMC Complement Altern Med 18(1): 89, 2018. PMID: 29534723. DOI: $10.1186 / \mathrm{s} 12906-018-2155-3$

29 Wang CC, Chiang YM, Sung SC, Hsu YL, Chang JK and Kuo PL: Plumbagin induces cell cycle arrest and apoptosis through reactive oxygen species/c-Jun $\mathrm{N}$-terminal kinase pathways in human melanoma A375.S2 cells. Cancer Lett 259(1): 82-98, 2008. PMID: 18023967. DOI: 10.1016/j.canlet.2007.10.005

30 Kawiak A, Zawacka-Pankau J and Lojkowska E: Plumbagin induces apoptosis in Her2-overexpressing breast cancer cells through the mitochondrial-mediated pathway. J Nat Prod 75(4): 747-751, 2012. PMID: 22512718. DOI: 10.1021/np3000409

31 Winter E, Chiaradia LD, Silva AH, Nunes RJ, Yunes RA and Creczynski-Pasa TB: Involvement of extrinsic and intrinsic apoptotic pathways together with endoplasmic reticulum stress in cell death induced by naphthylchalcones in a leukemic cell line: advantages of multi-target action. Toxicol In Vitro 28(5): 769-777, 2014. PMID: 24583196. DOI: 10.1016/j.tiv. 2014.02.002

32 Ott M, Robertson JD, Gogvadze V, Zhivotovsky B and Orrenius $\mathrm{S}$ : Cytochrome c release from mitochondria proceeds by a twostep process. Proc Natl Acad Sci USA 99(3): 1259-1263, 2002. PMID: 11818574. DOI: 10.1073/pnas.241655498

33 Madesh M and Hajnóczky G: VDAC-dependent permeabilization of the outer mitochondrial membrane by superoxide induces rapid and massive cytochrome c release. $\mathrm{J}$ Cell Biol 155(6): 1003-1015, 2001. PMID: 11739410. DOI: $10.1083 /$ jcb. 200105057
Received July 17, 2021

Revised August 9, 2021

Accepted August 26, 2021 